\title{
EVALUATION OF MEDIAN MAXILLARY LABIAL FRENUM TYPE AND MORPHOLOGY IN DIFFERENT AGE GROUPS
}

\author{
Gulser Kilinc ${ }^{1}$, Mujdet Cetin², Umran Ergun Ertunc ${ }^{3}$, Zafer Berk Kose ${ }^{1}$, Alp \\ Abidin Atesci ${ }^{4}$
}

${ }^{1}$ Dokuz Eylul University, Vocational Health High School, Mouth and Dental Health, Izmir, Turkey

2 Dokuz Eylul University, Faculty of Medicine, Children's Dental Clinic, Izmir, Turkey

${ }^{3}$ Dokuz Eylul University, Faculty of Medicine, Department of Public Health, Izmir, Turkey

${ }^{4}$ Private Practice, Izmir, Turkey.

Address for Correspondence: Gulser Kilinc, E-mail: gulser.kilinc@deu.edu.tr

Received: 01.03.2021; Accepted: 20.08.2021; Available Online Date: 20.09.2021

CCopyright 2021 by Dokuz Eylül University, Institute of Health Sciences - Available online at https://dergipark.org.tr/en/pub/jbachs

Cite this article as: Kilinc G, Cetin M, Ergun-Ertunc U, Kose ZB, Atesci A. Evaluation of Median Maxillary Labial Frenum Type and Morphology in Different Age Groups. J Basic Clin Health Sci 2021; 3: 30- 35.

\begin{abstract}
Introduction: The aim of this study is to evaluate the median maxillary labial frenum (MMLF) type and morphology and its associations with age and gender.

Methods: The present study was conducted on 1023 patients who attended to University Child and Adult Dental Clinic. Patients were divided into five age groups. The MMLF type and morphology of the patients were evaluated under dental unit light and classified according to the criterias described by Mirko et al. and Sewerin.

Results: 1023 patients included in the study, 51.4\% (524) were male and $49.9 \%$ (498) were female. In all groups, gingival type (55.2\%) frenum was the most frequently observed MMLF type, while simple frenum (66.9\%) was the most frequently observed MMLF morphology. Papillar and papillar penetration types were observed more frequently in GI, GII and GIII groups compared to the GIV and GV groups. Persistent tectolabial type frenum was observed in only 3 patients in $\mathrm{Gl}$ group and was not observed in any of the age groups. Although there were no significant differences were observed between MMLF type and gender, there were significant differences between MMLF type and age. MMLF is a small anatomical process yet it differs in type and morphology. It can be concluded that, with aging, the MMLF attachment level shifts from coronal to a more apical level.
\end{abstract}

Conclusions: The present study showed that, dental practitioners should be aware of the MMLF type and morphology variations in order to avoid excessive treatment especially in young patients.

Keywords: median maxillary labial frenum, morphology, type, age

\section{INTRODUCTION}

Median maxillary labial frenum (MMLF) is a residual mucose membrane which is commonly located between maxillary central incisors $(1,2)$. Histologically, MMLF is composed of (includes) connective tissue, epithelium, nerve fibers, elastic and collagen fibers (1-4). MMLF plays a key role in development of alveolar basal bone and translative growth of maxilla with its septomaxillary ligaments (5). Labial frenum provides stability to the upper lip and plays a role in mastication process (4). MMLF shows variations/changes in size, shape and position during different periods of human growth and development (6-8). While thick and wide MMLF was observed at 


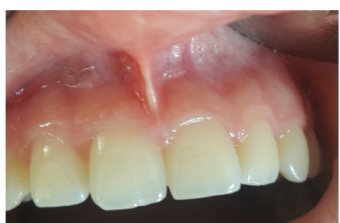

Simple

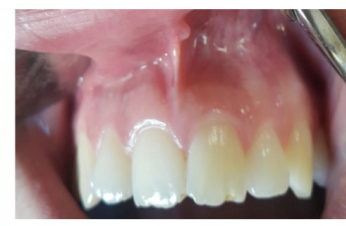

Simple with Nodule

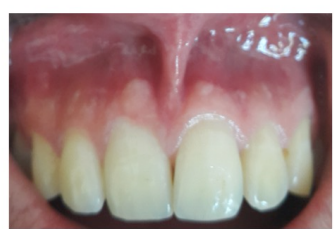

Bifid

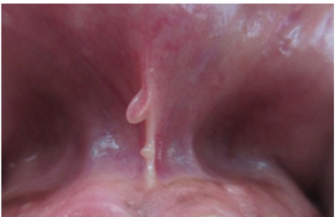

Nictum Labial

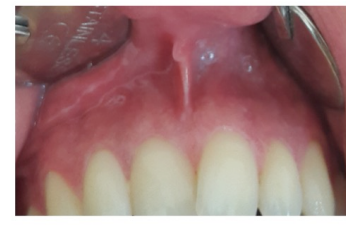

Simple with Appendix

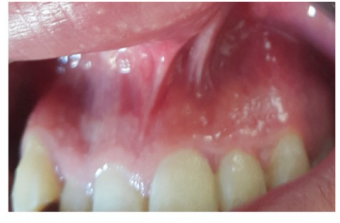

Double

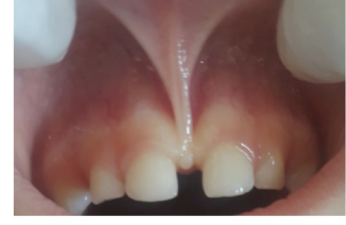

Persistent Tectolabial

Figure 2. Morphological type classificiation according to the classification of Sewerin (12)

early ages, it becomes thinner and smaller with time (4). With the eruption of the permanent teeth and increased growth of the alveolar process, this attachment completes its maturation process and may vary in size for each individual (9). MMLF abnormalities may be seen in the oral cavity due to several causes $(4,10,12)$. injuries to jaw and face in the early childhood may cause MMLF abnormalities as well as various syndromes which can cause malformations and gingival diseases (4). EhlerDanlos syndrome, Ellis-Van Creveld syndrome, Infantile Hypertrophic Pyloric Stenosis and Holoprosencephaly are one of the many syndromes associated with abnormal frenum $(4,10)$. Abnormal frenum might also be seen in healthy individuals without syndrome and it is known that it may cause several clinical problems. It is reported that when the frenum attachment level is too close to the gingival margin, it may cause gingival recession because of the muscle pull $(9,11)$.

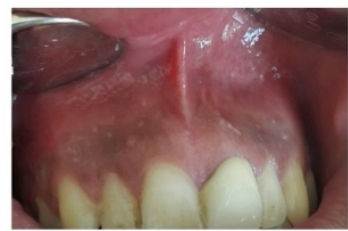

Mucosal

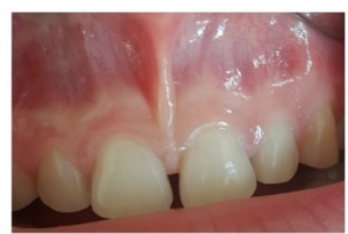

Papillar

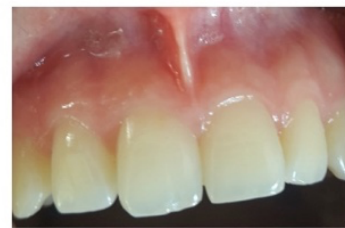

Gingival

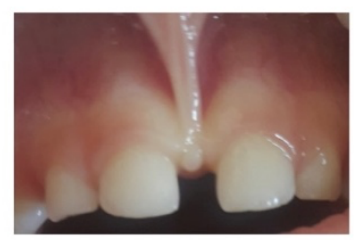

Papillar Penetration
Figure 1. Anatomical MMLF type classification according to the Mirko et al. (13)
Even though MMLF is a small anatomical process it may vary in anatomical attachment and morphological type $(4,7)$ Sewerin (12) reported eight different types of frenum (simple, simple appendix, nictum labial, simple with nodule, bifid, persistent tectolabial, double and no frenum) according to their morphological type while Mirko et al. (13) reported 4 types of frenum (mucosal, gingival, papillar and papillar penetration) according to their anatomical attachment.

Early gingival recession in maxillary anterior teeth, periodontal problems and limited movement of upper lip can be seen in papillary and papillary penetration type MMLF morphology unlike mucosal and gingival type frenum. In addition, retention problems of total prosthesis can be seen in papillar type MMLF morphology (10).

The aim of this study is to evaluate the morphology and types of MMLF and its associations with different age groups and gender. In addition this research will provide a main database source for future studies in this field.

\section{MATERIALS AND METHODS}

\section{Study Population}

This study was conducted on patients who were attended to Dokuz Eylul University Hospital Child and Adult Clinic. A prospective, cross-sectional unicentric study was conducted within January 2018 to December 2018. The age of the patients ranged between 2 to 65 years. The patients were divided into five age groups as follows. 
Group I (G I): 2-6 years (Primary dentition)

Group II (G II): 7-12 years (Mixed dentition)

Group III (G III): 13-18 years (Adolescents -

Permanent dentition)

Group IV (G IV): 19-39 years (Young adults Permanent dentition)

Group V (G V): 40-65 years (Middle aged patients Permanent dentition)

Table 1. Frequency distribution of patients according to the gender and age

\begin{tabular}{lll}
\hline Demographic Characteristics & N (\%) \\
\hline Gender & Male & $524(51.2)$ \\
& Female & $499(48.8)$ \\
\hline GI (2-6 years) & $197(19.3)$ \\
Age Group & GII (7-12 years) & $235(23.0)$ \\
& GIII (13-18 years) & $197(19.3)$ \\
& GIV (19-39 years) & $239(23.4)$ \\
& GV (40-65 years) & $155(15.2)$ \\
\hline
\end{tabular}

\section{Clinical Examination}

All procedures were approved by the University Ethics Committee on Human Research (3860-GOA 2018/07-18). Written consents of the patients were received for every patient and caregivers. The study did not involve any treatment and was mainly based on mere examination of frenum, Convenience sampling technique was used for sampling methodology.

All patients were examined under dental unit light using mouth mirror and examinations were carried out by three experienced dentists. Patients' anatomical MMLF type was classified according to the Mirko et al. (13) (Figure 1) and morphological type was classified according to the classification of Sewerin (12) (Figure 2). The calibration exercise performed with randomly selected 20 patients who had not participated in the study. Intra-examiner reliability was tested by Kappa statistics. The Kappa coefficient was 0.92 and the examiners were considered suitable for the study.

\section{Exclusion Criteria}

Patients with unerupted primary maxillary central incisors (age < 2) were excluded from the study. In addition patients with cleft lip/palate, hypodontia of maxillary incisors, congenital anomalies, oro-facial syndromes and with a history of traumatic injuries to the labial frenum were excluded from the study.

\section{Limitations of the Study}

The selected age interval (2-65 years old) and patients (who only attended University Hospital Child and Adult Clinic) have been seen as the most important limitations for this study since they are not able to represent the whole population.

\section{Statistical Analysis}

The actual and percentage-wise distribution of MMLF types and morphology was calculated. The relationship of frenum attachment with gender, and age were analysed. The collected data were calculated with SPSS for Windows 20.0 (IBM Corp., Chicago, USA) software using t test, chi square test and statistical significance was defined as $p<0.05$.

\section{RESULTS}

The study population included $524(51.4 \%)$ males and $498(49.9 \%)$ females with the total of 1023 patients. The frequency of distributions of the patients according to gender and age groups were shown in Table 1. There were no significant differences between the MMLF type and morphology with gender $(p=0,816)$.

In all of the age groups, gingival type attachment $(55.2 \%)$ was found to be the most common MMLF type which is followed by mucosal $(26.3 \%)$, papillary $(14.0 \%)$, and papillary penetrating type $(4.5 \%)$, (Table 2). There was a significant difference between MMLF attachment types and age groups $(p<0.001)$. In the GI group, similar levels of mucosal and gingival type were observed while gingival type was higher in the rest of the groups.

In the GV group, gingival type attachment $(77.4 \%)$ was observed as the most common MMLF type while mucosal and papillar type were observed more sparsely compared to the other age groups. Papillar and papillar penetration type MMLF were frequently observed in GI, GII and GIII age groups, while only two patients in GIV and only one patient in GV were observed.

Simple frenum $(66.9 \%)$ was found to be the most common MMLF morphology in all of the age groups which was followed by simple with appendix type frenum (17\%) (Table 3). Bifid type frenum prevalence was seen as $8.8 \%$ in all of the age groups and when compared to the other groups the highest prevalence was seen in the Gl group (18.3\%). A decrease in 
Table 2. Frequency distribution of MMLF morphology according to the age groups

\begin{tabular}{lllllll}
\hline $\mathbf{N}(\%)$ & G I & G II & G III & G IV & G V & Total \\
\hline Mucosal & $70(35.5)$ & $56(23.8)$ & $49(24.9)$ & $70(29.3)$ & $24(15.5)$ & $269(26.3)$ \\
\hline Gingival & $78(39.6)$ & $119(50.6)$ & $92(46.7)$ & $156(65.3)$ & $120(77.4)$ & $565(55.2)$ \\
\hline Papillar & $36(18.3)$ & $42(17.9)$ & $43(21.8)$ & $11(4.6)$ & $11(7.7)$ & $143(14.0)$ \\
\hline Papillar Penetration & $13(6.6)$ & $18(7.7)$ & $12(6.2)$ & $2(0.8)$ & $1(0.4)$ & $46(4.5)$ \\
\hline
\end{tabular}

GI: 2-6 years, GII: 7-12 years, GIII: $13-18$ years, GIV:19-39 years, GV: $40-65$ years.

Value $=102.491, \mathrm{P}<0.001$

prevalance of bifid frenum was observed with aging. The average prevalance of simple with nodule type frenum was $5.7 \%$ in all of the age groups and the highest percentage was observed in the GV group $(9.0 \%)$. Our results showed that the prevalance of simple with nodule type frenum increased with aging. Frenum with nichum $(0.9 \%)$ and double $(0.4 \%)$ type frenum prevalance were infrequently observed in all of the age groups. Persistent tectolabial type frenum was observed in only 3 patients in GI group and was not observed in any of the age groups. Patients without frenum were not observed in this study.

\section{DISCUSSION}

In this study, the correlation between type and morphology of MMLF and different age groups was investigated. Many of the studies on MMLF type and morphology were performed by choosing only one of the children, young or older age groups (1-3,6,7,9,1416). In our study, MMLF type and morphology in different age groups were evaluated $(4,6-8,14,17)$.

The classification of MMLF morphology developed by Mirko et al. (13) has been used in many studies as in our study as it is easily applicable to use for children, adolescents or adult patients.

There are studies indicating that the MMLF gingival type is seen at a high rate $(30.0-61.0 \%)$ (2$4,8,15,18)$, as well as studies indicating that the mucosal type is detected $(6,10,14,17,19)$. We attribute the reason for this difference to the age range of the selected population and the limited sample size. In our study, gingival type has been the most common $(55.2 \%)$ in all age groups. While the mucosal and gingival types were at similar levels in $\mathrm{Gl}$, it has been observed that the gingival type increased more with age. In the study of Biradar et al. which was coundected in patients aged between 3 to 17 years old, the prevalance of mucosal and gingival type MMLF morphology in ages between 3-6 years, was found to be similar (10).
In particular, papillary and papillary penetration was higher in $\mathrm{Gl}$ and Gll than in other age groups. Similarly, it has been stated in many studies that papillary and papillary penetration type attachment is more common in the young age group $(6,12,15)$. Pandiyan and Hedge (14) stated that the MMLF attachment may move from the coronal to the more apical level during the mixed dentition. According to the data obtained from our study, we conclude that the MMLF attachment site is closer to coronal level in children and adolescents, depending on the alveolar growth and development, moves towards the mucosal or gingival level as the age increases (8). In our study, the most common was simple frenum according to MMLF morphology (66.9\%) and the least common was persistent tectolabial frenum $(0.3 \%)$. In the previous studies, it was stated that the most frequent MMLF type was simple frenum was observed and the prevalence rate was found between $54-97 \%(4,6-8,10,14,15)$.

Diaz et al. (8), in their studies on the MMLF morphological types of 1355 Peruvian patients aged 0-6 years old, reported that the most common as simple frenum (59\%) and second most common as persistent tectolabial frenum ( $25 \%)$. They stated that they observed a high rate of persistent tectolabial frenum in the first six months ( $87 \%$ ) after birth, they did not encounter any patients in the age group of 6 and the midline diastema was closed with increasing age. Biradar et al. (10) reported that the prevalance of tectolabial frenum in children ages between 3-6 years old was $19.4 \%$ and decreased with age.

Pandiyan and Hedge (14) found $2.5 \%$ of persistent tectolabial frenum in 200 patients between the ages of 2-15 and stated that it has been observed only in the 2-6 age group. Christabel and Gurunathan (15) reported that they did not find persistent tectolabial frenum in 3-12 age group patients. Similar to these 
Table 3. Frequency distribution of MMLF type according to the age groups

\begin{tabular}{|c|c|c|c|c|c|c|}
\hline Frenum Type & $\begin{array}{l}\text { GI } \\
N(\%)\end{array}$ & $\begin{array}{l}\text { GII } \\
N(\%)\end{array}$ & $\begin{array}{l}\text { GIII } \\
N(\%)\end{array}$ & $\begin{array}{l}\text { GIV } \\
N(\%)\end{array}$ & $\begin{array}{l}\text { GV } \\
N(\%)\end{array}$ & $\begin{array}{l}\text { Total } \\
\text { N(\%) }\end{array}$ \\
\hline Simple & $120(60.9)$ & $176(74.9)$ & $135(68.5)$ & $151(63.2)$ & $102(65.8)$ & $684(66.9)$ \\
\hline SA & $29(14.7)$ & 34 (14.5) & $34(17.3)$ & $53(22.2)$ & $24(15.5)$ & $174(17.0)$ \\
\hline $\mathrm{BL}$ & $36(18.3)$ & $14(6.0)$ & $10(5.1)$ & $16(6.7)$ & $14(9.0)$ & $90(8.8)$ \\
\hline SN & $7(3.6)$ & $8(3.4)$ & $14(7.1)$ & $15(6.3)$ & $14(9.0)$ & $58(5.7)$ \\
\hline $\mathrm{NL}$ & - & $2(0.9)$ & $4(2.0)$ & $2(0.8)$ & $1(0.6)$ & $9(0.9)$ \\
\hline Double & $2(1.0)$ & $1(0.4)$ & - & $2(0.8)$ & - & $5(0.4)$ \\
\hline PTL & $3(1.5)$ & - & - & - & - & $3(0.3)$ \\
\hline
\end{tabular}

GI: 2-6 years, GII: 7-12 years, GIII: $13-18$ years, GIV:19-39 years, GV: $40-65$ years.

SA: Simple with appendix. BL: Bifid Labial, SN: Simple with nodule,

NL: Nictum Labial, PTL: Persistent tectolabial

studies, we observed persistent tectolabial frenum only in $\mathrm{GI}(0.3 \%)$ and did not in other groups.

In our study, simple with appendix (17.0\%) was the second most common MMLF morphology, followed by bifid $(8.8 \%)$, simple with nodule $(5.7 \%)$ frenum with nichum $(0.9 \%)$ and double frenum $(0.4 \%)$, no patient without frenum was observed. While there was no significant difference between age groups and simple with appendix frenum, the prevalence of simple with nodule frenum increased with age. Bifid frenum was seen at a higher rate in $\mathrm{Gl}$ and the prevalence decreased with aging. In the study of Sewerin (12), similar to our study, they reported simple with appendix as $17.4 \%$ and stated that it is the second most common morphological type. There are studies stating that the prevalance of simple with appendix frenum as the second highest (12), as well as studies stating that simple with nodule frenum $(6,7,16)$. Dasgupta et al. (17) found that the rate of frenum with nichum was $0.8 \%$ in their studies with 574 years old patients. Kakodkar et al. (19) reported only one patient with no frenum in their study in 1206 patients aged 12-17 years. Researchers stated that the prevalance of frenum with nichum, double and the patients without frenum in the population is below 1 $\%(10,15,19)$. These observations suggest that frenum with nichum, double and patients without frenum, despite the age, ethnic and racial differences the distribution ratio may be similar.

\section{CONCLUSION}

Although MMLF is a small anatomical process, it differs in type and morphology. It is known that as the age increases, the level of attachment of the frenum shifts from the coronal to the apical. In particular, monitoring patients with persistent tectolabial frenum should not consider surgical intervention immediately. For this reason, it is very important for dentists to know MMLF type and morphological variations to avoid misdiagnosis and excessive treatment.

Author contributions: Kilinc G. conceived the ideas, Kilinc G, Atesci AA, Kose ZB, Cetin M and Ertunc UE led the writing, Kilinc $G$, and Ertunc UE collected and analysed the data, Kilinc G, Kose $Z B$, Cetin M completed the examinations.

Conflict of interest: All authors deny any conflicts of interest related to this study.

Ethical Approval: All procedures were approved by the Dokuz Eylul University Ethics Committee on Human Research (3860GOA 2018/07-18). All procedures performed in studies involving human participants were in accordance with the ethical standards of the institutional and/or national research committee and with the 1964 Helsinki declaration and its later amendments or comparable ethical standards.

Funding: This work was not supported by any organization.

Informed Consent: Informed consent was obtained from all individual participants included in the study.

Peer-review: Externally peer-reviewed.

\section{REFERENCES}

1. Boutsi E, Tatakis D. Maxillary labial frenum attachment in children. Int J Paediatr Dent. 2011; 21:284-288.

2. Upadhyay S, Ghimire N. Atachment of maxillary labial frenum in Nepalese children. Orthodontic $\mathrm{J}$ Nepal. 2012; 2:28-31.

3. Bervian J, Cazarotto F, Perussolo B, Patussi EG, Pavinato LCB. Description of the upper labial frenulum characteristics in preschool children of Passo Fundo, Brazil. Braz Res Pediatr Dent Integr Clin. 2016; 16:351-357.

4. Niazi M, Shahroz N, Sajjad S, Haroon S. Morphological and attachment variations of median maxillary labial frenum. POJ. 2017;9: 1923.

5. Rajani ER, Biswas PP, Emmatty R. Prevalence of variations in morphology and attachment of 
maxillary labial frenum in various skeletal patterns - A cross-sectional study. J Indian Soc Periodontol. 2018; 22: 257-262.

6. 6-Jindal V, Kaur R, Goel A, Mahajan A, Mahajan $\mathrm{N}$, Mahajan A. Variations in the frenal morphology in the diverse population: A clinical study. J Indian Soc Periodontol. 2016; 20:320-323.

7. Mohan R, Soni PK, Krishna MK, Gundappa M. Proposed classification of median maxillary labial frenum based on morphology. Dent Hypothesis. 2014; 5: 16-20.

8. 8-Santa Maria C, Aby J, Truong MT, Thakur Y, Rea S, Messner A. The superior labial frenulum in newborns: what is normal? Glob Pediatr Health. 2017; 4: 1-6.

9. Díaz-Pizán $M$, Lagravère $M$, Villena R. Midline diastema and frenum morphology in the primary dentition. J Dent Child. 2006; 73:11-14.

10. Biradar SM, Patil AY, Kotnoor SS, Shraddanand Bacha S, Bijjaragi SC, Kattimani PT. Assessment of Diverse Frenal Morphology in Primary, Mixed, and Permanent Dentition: A Prevalence Study. J Contemp Dent Pract.2020;21:561-567.

11. Needleman I. Aging and Periodontium. In: Caranza F, Newman M, editors. Caranza's Clinical Periodontology. 11th ed2012. p. 28-30.

12. Sewerin I. Prevalence of variations and anomalies of the upper labial frenum. Acta Odontol Scand. 1971; 29:487-496.

13. Mirko P, Miroslav S, Lubor M. Significance of the labial frenum attachment in periodontal disease in man. Part I. Classification and epidemiology of the labial frenum attachment. J Periodontol. 1974; 45:891-894.

14. Pandiyan NJ, Hedge A. Clinical assessment of frenum morphology and attachment in Malaysian children. Pesq Bras Odontoped Clin Integr. 2018; $18: 1-9$.

15. 15-Christabel SL, Gurunathan D. Prevalence of type of frenal attachment and morphology of frenum in children, Chennai, Tamil Nadu. World J Dent. 2015; 6: 203-207.

16. 16.Nadar S. Maxillary labial frenum attachment in children of different age groups. Int $\mathrm{J}$ Current Rese. 2017; 9: 50367-50369.

17. Dasgupta P, Kamath G, Hs S, Babshet M, Doddamani L. Morphological variations of median maxillary labial frenum: A clinical study. J Stomatol Oral Maxillofac Surg. 2017; 118: 337341.
18. Seraj $B$, Shahrabi M, Masoumi $S$, Jabbarian $R$, Manesh A, Baghizadeh Fini M. Studying Maxillary Labial Frenulum Types and Their Effect on Median Diastema in 3-6-year-old Children in Tehran Kindergartens. World J Dent. 2019:10:93-97.

19. Kakodkar PV, Patel TN, Patel SV, Patel SH. Clinical assessment of diverse frenum morphology in permanent dentition. Internet $\mathrm{J}$ Dent Sci. 2008; 7: 1-8. 